\title{
An object missed 10 years before
}

\author{
Leonor Castro Ferreira, ${ }^{1}$ Ana Carmo Casquilho, ${ }^{2}$ Eunice Capela, ${ }^{2,3}$ João Dias ${ }^{2}$
}

${ }^{1}$ Department of Obstetric and Gynecology, Faro Hospital, Faro, Portugal

${ }^{2}$ Department of Gynecology, Faro Hospital, Faro, Portugal ${ }^{3}$ Department of Biomedical Sciences and Medicine, University of Algarve, Faro, Portugal

\section{Correspondence to} Dr Leonor Castro Ferreira, nonopbull@gmail.com

Accepted 3 April 2015
CrossMark

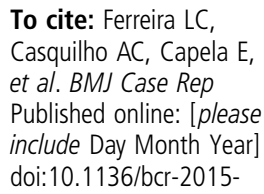

\section{DESCRIPTION}

A 36-year-old woman, gravida 3 para 1, with a first trimester abortion and a vaginal delivery, presented with a 5-month history of pelvic pain and occasional fever. The abortion had been performed 10 years prior to this episode, outside medical facilities. The patient had irregular menses, and reported dysmenorrhoea and pelvic pain that started simultaneously. Her abdominal examination was significant for lower quadrant tenderness. At vaginal examination, there was no vaginal discharge and the uterus was partially fixed.

At admission, a bedside ultrasound evaluation showed a tubular foreign body with an extremity in the uterine cavity. This observation was confirmed by $\mathrm{t}$-contrast-enhanced pelvic CT scan, which showed a foreign body (figure 1) partially located in the uterus and partially in the pelvic cavity (figure 2). The patient underwent diagnostic laparotomy. During the procedure the presence of a foreign body was confirmed (figure 3 ). The foreign body was $300 \times 20 \mathrm{~mm}$ and perforated the uterus with fistulisation to the sigmoid colon, terminal ileum and left ureter. These observations are compatible with perforation of the uterus by a blunt object. A segmental resection of the left ureter, and partial resection of the ileum and sigmoid colon, followed by a colostomy, were performed. The uterus perforation was sutured following the removal of the foreign body. Microbiological study of the foreign body was performed, with negative result. The specimen,

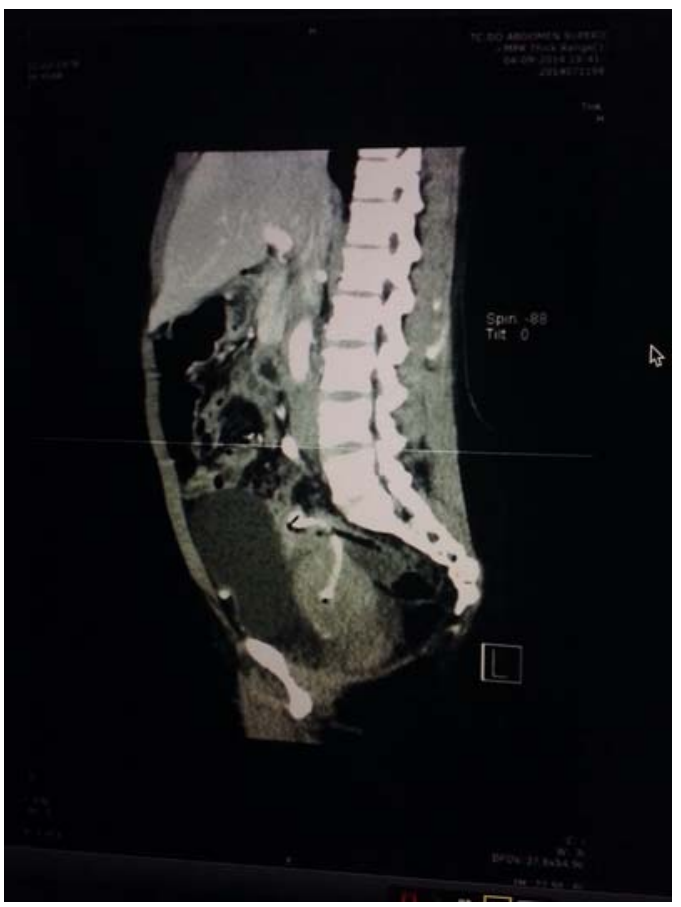

Figure 1 Sagittal pelvic CT image revealed a high-density tubular structure, suggesting a foreign body.

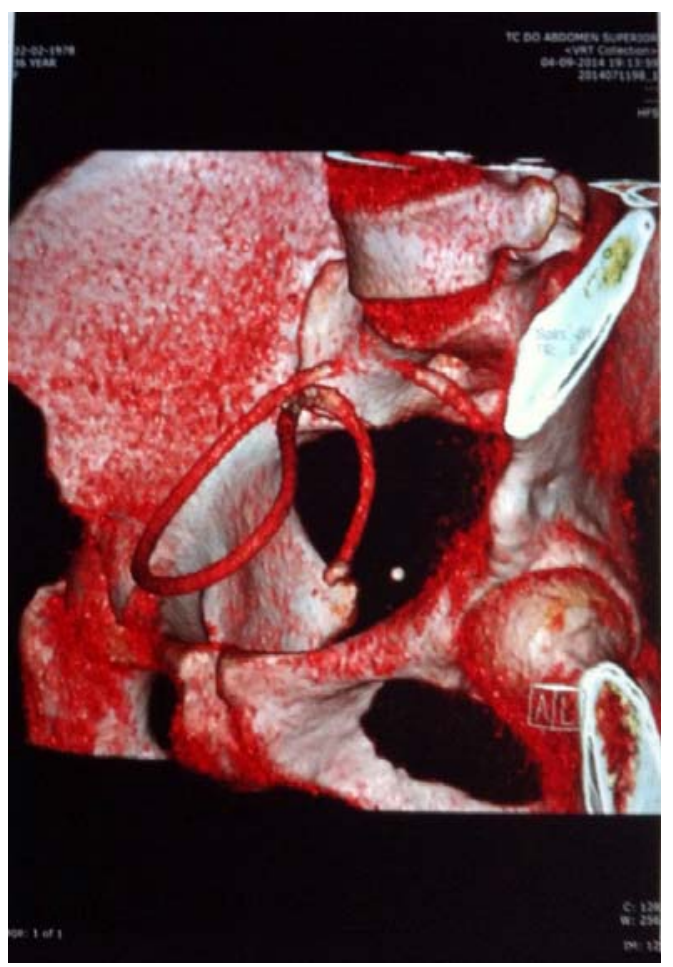

Figure 2 Three-dimensional tomographic reconstruction of pelvic region allowed for the observation of the location of the foreign body.

tubular shaped, measuring $31 \times 2 \mathrm{~cm}$ was identified as a flexible electric wire covered with plastic.

A 3-week hospital stay was complicated by ileus that resolved spontaneously.

The WHO defines unsafe abortion as a procedure for terminating a pregnancy by persons lacking the appropriate skills, or in an environment not in conformity with minimal medical standards, or both. Complications of this type of procedure occur in $25 \%$ of women undergoing an unsafe abortion. ${ }^{1}$ When uterine instrumentation is used,

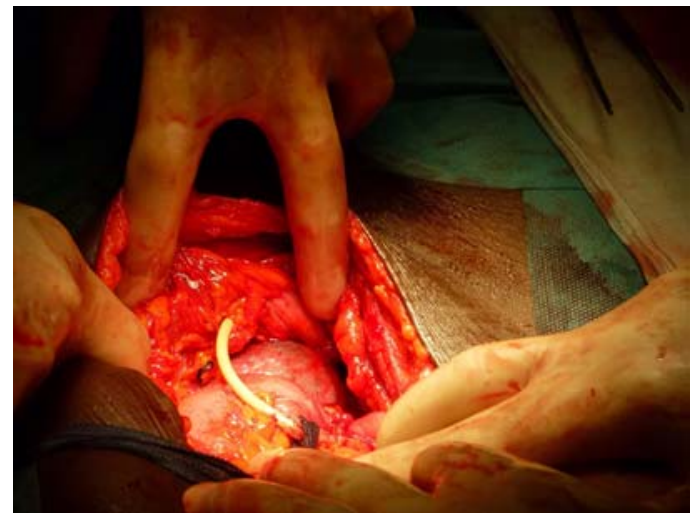

Figure 3 Laparotomy revealed the presence of a tubular structure perforating the uterus. 
uterine perforation is common followed by perforation of the fallopian tubes, ovaries, bowel, rectum and bladder. $^{2}$

\section{Learning points}

- The most common complications of unsafe abortion are trauma, infection and genital bleeding.

- Most women will not report the procedure, so if clinical findings are present the clinician must have an enhanced suspicion for unsafe abortion.

- Unsafe abortion is a major factor in maternal morbidity and mortality, with high economic costs since complications of this type of procedure may create a need for hospital care.
Competing interests None declared.

Patient consent Obtained.

Provenance and peer review Not commissioned; externally peer reviewed.

\section{REFERENCES}

1 World Health Organization, Department of Reproductive Health and Research. Unsafe abortion: global and regional estimates of incidence of unsafe abortion and associated mortality in 2003. 5th edn. Geneva: WHO, 2007.

2 Sing S, Wulf D, Hussain R, et al. Abortion worldwide: a decade of uneven progress. New York: Guttmacher Institute, 2009.

Copyright 2015 BMJ Publishing Group. All rights reserved. For permission to reuse any of this content visit

http://group.bmj.com/group/rights-licensing/permissions.

BMJ Case Report Fellows may re-use this article for personal use and teaching without any further permission.

Become a Fellow of BMJ Case Reports today and you can:

- Submit as many cases as you like

- Enjoy fast sympathetic peer review and rapid publication of accepted articles

- Access all the published articles

- Re-use any of the published material for personal use and teaching without further permission

For information on Institutional Fellowships contact consortiasales@bmjgroup.com

Visit casereports.bmj.com for more articles like this and to become a Fellow 